\title{
Lack of association between IRF6 polymorphisms and nonsyndromic oral clefts in South Indian population
}

\author{
Venkatesh Babu Gurramkonda ${ }^{1}$, Jyotsna Murthy ${ }^{2}$, Altaf Hussain Syed ${ }^{2}$, and Bhaskar VKS Lakkakula ${ }^{1}$ \\ ${ }^{1}$ Department of Biomedical Sciences, Sri Ramachandra University, Chennai, India. \\ ${ }^{2}$ Department of Plastic Surgery, Sri Ramachandra University, Chennai, India.
}

\section{Abstract}

Objective: This present study is aimed to investigate the association between interferon regulatory factor 6 (IRF6), single nucleotide polymorphisms (SNPs), and nonsyndromic cleft lip without without cleft palate (NSCLP) in the South Indian population. Subject and Methods: For this study, 190 unrelated NSCLP patients and 189 controls without clefts were genotyped with rs2235371 (V2741) and rs642961 SNPs using PCR-RFLP. The associations between NSCLP groups and IRF6 gene polymorphisms, as well as haplotypes, were analyzed using chi-squared test and $95 \%$ confidence interval $(95 \% \mathrm{Cl})$ of the odds ratios were calculated with the control groups as reference.

Results: For controls, the minor allele frequencies of both variants, V2741 and rs642961, were $7.1 \%$ and $21.1 \%$, respectively. Genotype data for both variants in control and cleft groups follow the Hardy Weinberg Equilibrium. Between cases with NSCLP and controls, the two SNPs showed no differences in frequencies of the genotypes or alleles. The pairwise linkage disequilibrium (LD) values $\left(D^{\prime}=1\right.$ and $\left.r^{2}=0.027\right)$ between V2741 and rs642961 revealed that these two SNPs are not in strong LD. Haplotype G-T showed a significantly reduced risk for oral clefts $(p<0.001)$ and haplotype A-T increased the risk for oral clefts $(p=0.043)$. Gene-gene interaction showed that the higher risk group contains more GG-CC combination of cases that the controls, but this model was not significantly associated with cleft status ( $p=0.136)$

Conclusion: In conclusion, while IRF6 is strongly associated in other populations, this study demonstrated that variants in IRF6 may play a role in NSCLP in a South Indian population, but other genes are expected to play a role in this population as well.

\section{Introduction}

Cleft lip with or without cleft palate is an extremely complex orofacial birth defect and is found to be more common in Asian and Asian-American populations and less common in Africans and African-Americans. Roughly $70 \%$ of CLP cases are nonsyndromic, occurring as an isolated condition, while the remaining $30 \%$ of CLP cases are present in association with syndromes [1]]. Converging lines of evidence suggest that the nonsyndromic cleft lip with or without cleft palate (NSCLP) involves interplay of both genetic and environmental factors. NSCLP most often occurs as an isolated defect in families with no history of clefts. NSCLP gene identification is difficult because of varying levels of penetrance, sex differences, and environmental overlays that increase etiological heterogeneity [ㄹ] Despite having a substantial genetic component, only a fraction of all predisposing genes have been convincingly confirmed as playing role in NSCLP. Many genes associated with syndromic cases of CLP have been identified to contribute to the incidence of NSCLP [3]]. This approach led to the identification of several genes that contribute to the isolated clefting [4-9]. Van Der Woude syndrome (VWS; OMIM 119300) is the most common autosomal dominant clefting syndrome and is distinguished by the presence of highly characteristic pitting of lower lip mucosa and CLP [ $\underline{10}]$. The VWS locus was initially mapped to human chromosome 1q32-q41 region that harbors interferon regulatory factor 6
Citation: Gurramkonda VB, Murthy J, Syed AH, and Lakkakula BVKS (2013) Evidence of association between IRF6 polymorphisms and nonsyndromic oral clefts in South Indian population. Dentistry 3000 1:a001 doi:10.5195/d3000.2013.9 Received: March 25, 2013

Accepted: June 20, 2013

Published: August 1, 2013

Copyright: (C2013 Gurramkonda et al. This is an openaccess article licensed under a Creative Commons Attribution 3.0 United States License. Email: Ivksbhaskar@gmail.com
(IRF6) gene [11]. Numerous mutations in the IRF6 were reported to cause VWS [1114].

The IRF6 gene encodes a transcription factor characterized by a highly conserved DNA-binding domain in addition to a less well-conserved protein interaction domain [15]. Several polymorphisms in the IRF6 gene have been studied to check their association with cleft lip and palate, but the results are inconclusive. Genome-wide and candidate gene studies and a subsequent meta-analysis have identified IRF6 as a plausible gene contributing to cleft lip and palate in different ethnicities [16-18]. The present study is aimed to investigate the association between IRF6 single nucleotide polymorphisms and NSCLP in a South Indian population. We chose two markers:

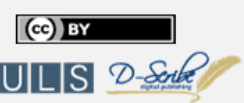

This work is licensed under a Creative Commons Attribution 3.0 United States License.

This site is published by the University Library System, University of Pittsburgh as part of its D-Scribe Digital Publishing Program and is cosponsored by the University of Pittsburgh Press. 
rs2235371 (V274I), a non-synonymous SNP, and rs642961, located in the newly identified IRF6 enhancer region. In addition to this, HapMap data on these polymorphisms in GIH samples (Gujarati - a West Indian population) showed that these SNPs are polymorphic and located in two different linkage disequilibrium (LD) blocks. Since the present study population is nearest to GIH, it is likely that these two polymorphisms are the best fit for the study undertaken.

\section{Materials and Methods}

Subjects:

This study included a total of 379 individuals of South Indian origin. One hundred ninety unrelated NSCLP patients who were admitted for palatoplasty and lip repair were ascertained at Sri Ramachandra cleft and craniofacial centre, Sri Ramachandra University, Chennai, India. To determine their individual phenotype status, all of the cases were examined by two clinicians. Oral clefts with other congenital malformations or major developmental disorders were excluded from the study. All of the cases are isolated, nonsyndromic oral clefts and were classified into two groups: cleft lip with or without cleft palate (CLP) and cleft palate only (CPO). All patients with oral clefts were screened for history, consanguinity, affected members in family and relatives, gestational history, drug intake, smoking, alcohol consumption, etc. We recruited 189 age- and sex-matched normal children without family history of birth defects and considered this as the control group. Power and sample size calculation software (version 2.1.31) was used to calculate the sample sizes in the study. We used an uncorrected chi-squared statistic to evaluate this null hypothesis. Based on power analysis, a study with 190 case patients and 190 controls was large enough to detect a significant odds ratio (OR) of 0.5 with a power of $85.8 \%$ and an alpha of $5 \%$ and a minor allele frequency difference of 0.15 between cases and controls. The study was approved by the Institutional Ethics Committee of Sri Ramachandra University, Chennai, India. As many of the subjects are under 15 years of age, consent was requested from their parents. Three milliliters of blood sample was collected from all the participants after obtaining the informed consent.

\section{Genotyping:}

Genomic DNA was extracted from the samples by phenol chloroform extraction and ethanol precipitation protocol [19]. The V274I and rs642961 SNPs of the IRF6 gene were amplified by polymerase chainreaction (PCR) with primers published elsewhere [20] . Genotyping for the two SNPs was carried out by restriction digestion of the PCR products with $\mathrm{Mbol}$ and BstNI restriction enzymes, respectively. For the V274I polymorphism, $\mathrm{Mbol}$ digests the $\mathrm{G}$ allele in five fragments [322, 177, 80, 35, and 33 base pairs (bp)], whereas the A allele adds another restriction site, allowing the $322 \mathrm{bp}$ fragment to be digested into two smaller pieces of 235 and $87 \mathrm{bp}$. Digestion of the rs642961 PCR products with BstNI results in three fragments $(213,33$, and 30 bp) for the $C$ allele and two fragments (246 and $30 \mathrm{bp}$ ) for the T allele [20].

\section{Statistical analysis:}

Allele frequencies were estimated based on the gene count method. The genotypic frequencies for V274I and rs642961 were evaluated for Hardy-Weinberg equilibrium by using a Monte Carlo permutation test implemented in the HWSIM program [21]. All frequencies were in agreement with Hardy-Weinberg equilibrium. The associations between NSCLP groups and IRF6 gene polymorphisms, as well as haplotypes, were analyzed using chi-squared test, and 95\% confidence interval $(95 \% \mathrm{CI})$ for the odds ratios were calculated with the control group as reference. Linkage disequilibrium values of $\mathrm{D}^{\prime}$ and $\mathrm{r}^{2}$ were estimated using
HaploView 3.12 [22]. Haplotypes were constructed using ARLEQUIN program [르] Multifactor Dimensionality Reduction (MDR) 2.0.beta.8.4 software was used to detect the gene-gene interactions[24].

\section{Results}

Genotyping by RFLP and electrophoresis on the DNA samples of all cleft and control individuals was performed. HardyWeinberg expectations were fulfilled in controls for both V274I $(\mathrm{p}=0.964)$ and rs642961 $(p=0.260)$ SNPs. For V274I, the distribution of mutant allele and genotypes was not significantly different between NSCLP groups and controls (Table 1). Mutant allele (Ile) was less in controls (7.1\%) than the cleft groups (CLP 9.9\% and CPO $11.7 \%$ ) and the difference is not statistically significant for CLP and CPO with ORs of 1.41 (CI, 0.80-2.50; $\mathrm{p}=0.208$ ) and 1.73 (CI, 0.60$4.33 ; \mathrm{p}=0.219$ ), respectively (Table 2). Comparison of individual genotype frequencies between NSCLP groups and controls did not reveal association between the V274I genotype and type of cleft (Table 1). Although, in the present study the mutant genotypes $(\mathrm{GA}+\mathrm{AA})$ increased the risk in both NSCLP groups, the increase in risk is not statistically significant (Table 1). Similarly, the enhancer polymorphism (rs642961) also failed to demonstrate significant differences in genotype frequencies between controls and NSCLP groups (Table $1)$. The pairwise $L D$ values $\left(D^{\prime}=1\right.$ and $r^{2}=0.027$ ) between V274I and rs642961 also revealed that these two SNPs are not in strong LD. The haplotypes, constructed by using two polymorphic SNPs, are provided in Table 3. The G-T haplotype was the second major haplotype in both cases $(10.0 \%)$ and controls $(20.0 \%)$ and showed a significantly reduced risk for oral clefts $(\mathrm{p}<0.001)$. Whereas, the rare haplotype A-T, formed of two minor alleles of V274I and rs642961 polymorphisms, increased the risk for oral clefts $(p=0.043)$. Using the MDR analysis, the best MDR models for the studied SNP

Table 1: Results of association tests with IRF6 gene polymorphisms in case and control groups.

\begin{tabular}{|c|c|c|c|c|c|c|c|c|}
\hline & & & & & & OR $(95 \% \mathrm{Cl})$ & OR $(95 \% \mathrm{Cl})$ & OR $(95 \% \mathrm{Cl})$ \\
\hline SNP. ID & Group & GG (\%) & GA (\%) & AA (\%) & $p$ value & GG vs. GA & GG vs. $A A$ & GG vs. $(G A+A A)$ \\
\hline \multirow[t]{6}{*}{ V274I } & Control & $164(86.32)$ & $25(13.16)$ & $1(0.53)$ & & & & \\
\hline & CLP & $129(81.24)$ & $29(8.24)$ & $1(0.63)$ & 0.419 & $1.47(0.82-2.64)$ & $1.27(0.07-20.52)$ & $1.47(0.82-2.60)$ \\
\hline & $\mathrm{CPO}$ & $23(76.67)$ & $7(23.33)$ & $0(0.00)$ & 0.318 & $1.99(0.77-5.13)$ & - & $1.73(0.60-4.33)$ \\
\hline & Total & $152(80.42)$ & $36(19.5)$ & $1(0.53)$ & 0.295 & $1.55(0.86-2.81)$ & $1.08(0.01-85.2)$ & $1.4(0.86-3.75)$ \\
\hline & & & & & & OR $(95 \% \mathrm{Cl})$ & OR $(95 \% \mathrm{Cl})$ & OR $(95 \% \mathrm{Cl})$ \\
\hline & Group & CC (\%) & CT (\%) & TT (\%) & $p$ value & CC vs. $\mathrm{CT}$ & CC vs. TT & CC vs. $(\mathrm{CT}+\mathrm{TT})$ \\
\hline \multirow[t]{4}{*}{ rs642961 } & Control & $121(63.68)$ & $58(30.53)$ & $11(5.79)$ & & & & \\
\hline & CLP & $90(56.60)$ & $55(34.59)$ & $14(8.81)$ & 0.323 & $1.27(0.80-2.01)$ & $1.7(0.74-3.94)$ & $1.34(0.87-2.06)$ \\
\hline & $\mathrm{CPO}$ & $22(73.33)$ & $8(26.57)$ & $0(0.00)$ & 0.326 & $0.76(0.31-1.80)$ & - & $0.64(0.26-1.50)$ \\
\hline & Total & $112(59.26)$ & $63(34.59)$ & $14(8.81)$ & 0.633 & $1.17(0.74-1.87)$ & $1.38(0.56-3.41)$ & $1.21(0.78-1.86)$ \\
\hline
\end{tabular}


Table 2: Results of allelic association tests for IRF6 gene polymorphisms in case and control groups.

\begin{tabular}{|c|c|c|c|c|}
\hline \multicolumn{5}{|c|}{ V274I } \\
\hline Group & G (\%) & $A(\%)$ & $p$ value & OR $(95 \% \mathrm{Cl})$ \\
\hline Control & $353(92.8)$ & $27(7.10)$ & \multicolumn{2}{|c|}{ Reference } \\
\hline CLP & $287(90.25)$ & $31(9.74)$ & 0.208 & $1.41(0.80-2.50)$ \\
\hline $\mathrm{CPO}$ & $53(88.3)$ & $7(11.66)$ & 0.219 & $1.73(0.60-4.33)$ \\
\hline \multirow[t]{3}{*}{ Total } & $340(89.94)$ & $38(10.05)$ & 0.17 & $1.46(0.85-2.52)$ \\
\hline & \multicolumn{3}{|c|}{ rs642961 } & \\
\hline & $\mathrm{C}(\%)$ & $\mathrm{T}(\%)$ & $p$ value & OR $(95 \% \mathrm{Cl})$ \\
\hline Control & $300(78.94)$ & $80(21.05)$ & & ference \\
\hline CLP & 235(73.89) & $83(30.81)$ & 0.116 & $1.32(0.92-1.91)$ \\
\hline $\mathrm{CPO}$ & $52(86.66)$ & $8(0.13)$ & 0.164 & $1.58(0.24-1.32)$ \\
\hline Total & $287(75.92)$ & $91(25.07)$ & 0.319 & $1.190(0.83-1.70)$ \\
\hline
\end{tabular}

\begin{tabular}{ccccc} 
Haplotype & Control (\%) & Oral clefts (\%) & OR(95\%Cl) & p-value \\
\hline G-C & $277(72.9)$ & $296(78.3)$ & Reference & \\
G-T & $76(20.0)$ & $38(10.0)$ & $0.47(0.31-0.71)$ & $<0.001$ \\
A-C & $23(6.1)$ & $31(8.3)$ & $1.26(0.72-2.22)$ & 0.419 \\
A-T & $4(1.1)$ & $13(3.3)$ & $3.04(0.98-9.44)$ & 0.043 \\
\hline
\end{tabular}

IRF6 is exhibiting zygosity showed evidence for altered 89\% similarity transmission of three of the four SNPs in with IRF5, which Italians with CLP [32]. This positive associaplays a major role tion between NSCLP and IRF6 was conin interferon acti- firmed in American populations [33], and vation and tumor Belgian populations [34]. Comparison of suppression [25]. CLP family members and controls revealed combination is shown in Figure 1. The two- Although a role for IRF6 during embryonic SNP model containing the IRF6 V274I and development has been identified, its funcrs642961 markers had a testing accuracy tion and regulation remain unknown [26, (TA) of 0.541 and cross-validation con- 27].However, recent studies show that IRF6 sistency (CVC) of $10 / 10$. However, this is regulated primarily through the enhancer model was not significantly associated with where rs642961 resides by p63 and AP2cleft status ( $p=0.136)$; the higher risk group alpha [28]. contains more GG-CC combination of cases than the controls (Figure 1).

\section{Discussion}

Interferon regulatory factor $6(I R F 6)$ is a member of the IRF family of transcription factors that share a highly conserved helixturn-helix DNA-binding domain and a less conserved protein-binding domain. The function of IRF6 is still unknown because it is not linked to the regulatory pathways or functions associated with other IRF family members. However, amino acid sequence alignment analysis demonstrated that the

Figure 1: Graphical representation of interaction analysis between V274I and rs642961 in NSCLP by MDR.

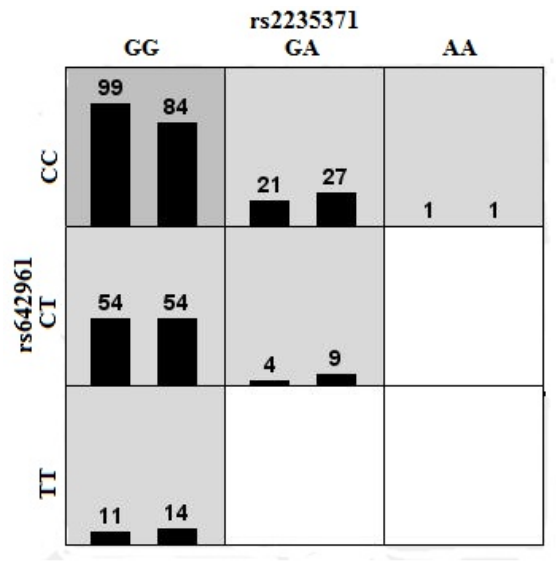

Value within each cell is combined genotypes and color-coding represents degree of risk. Dark grey is high-risk, light grey is low risk, empty cell is not a possible combination.
Under normal conditions, the vertical palatal shelves elevate above the tongue, grow horizontally towards each other, and come in contact at the medial edge epithelium (MEE) region along the facial midline. Subsequently, the thin medial edge epithelial lining is eliminated and the surrounding mesenchyme migrates inward and fuses the palatal cleft. During this process, IRF6 expression in the MEE rapidly increases, leading to dramatic morphological and cell specification changes, allowing palatal fusion [12]. A recent study demonstrated that IRF6 knockout mice failed to express TGFA in palatal tissues [29]. Furthermore, IRF6 expression in MME is mediated by TGF $\beta$ signaling [30]. The functional polymorphism rs2235371(820G>A) replaces a valine with an isoleucine at amino acid position 274 (V274I) of the SMIR-binding domain of IRF6. Another variant, rs642961 (G>A), is located 10 kilobases upstream of the transcription start site of IRF6. This disrupts the binding site of the transcription factor AP$2 \alpha$, which plays role in craniofacial development [31].

Analysis of two important IRF6 gene polymorphisms in 190 NSCLP patients and 189 controls of South Indian origin has not supported the association at neither genotype nor allele level with NSCLP. Haplotype analysis, however, provided indication that IRF6 contributes to NSCLP in the studied population. Over-transmission of $274 \mathrm{~V}$ allele in CLP subjects has been identified as a risk factor in Asians and South Americans, but it is not as strong in European populations [16]. A replication study that was conducted using four IRF6 SNPs that have high hetero that the GG genotype increased the risk of CLP in Thai populations [35]. The V274I polymorphism was significantly associated with NSCLP in different populations, such as South America [36], Chile [37], West China [38], Honduras [39], Norway [40] and Spanish Honduras [39]. Conversely, positive association was not reported in a German population where the frequency of $274 \mathrm{~V}$ allele is $99.4 \%$ [41]. Although TDT haplotype analysis showed significant association between NSCLP and IRF6 haplotypes, V274I is not associated with NSCLP in Chileans and Chinese, where the V274 allele frequency is $74 \%$ and $75 \%$, respectively $[37,42]$. In an Indian population, the V274I alone contributed to minor risk, but the risk is increased when the V274 allele is present in homozygous condition in combination with MTHFR 677CT [43].

Based on the published sources, the V274I polymorphism showed wide variations in the minor allele frequencies (274I allele); Africans $0 \%$, Europeans $0 \%$ to $10 \%$ [16], Hispanic and non-Hispanic populations 7\% and $22 \%$, respectively [44]. However, East Asians and Southeast Asian populations reported the highest frequencies: $34 \%$ and $42 \%$, respectively [16]. HapMap data also showed wide variations in the V274I minor allele frequency in world populations with highest frequency in CHD (42.1\%), CHB (41.1\%), JPT (40.6\%) and MEX (16.7\%) populations, whereas lowest frequency was observed in YRI (0.7 \%), LWK (0.5\%), ASW (1.8\%), TSI (0.5\%) and CEU (3.2\%) populations. Gujarati Indian population $(\mathrm{GIH} ; 8.6$ $\%$ ) exhibited fairly lesser frequencies than the East Asian populations. This high frequency of the $274 \mathrm{~V}$ allele in Indian and European populations yielded a nonsignificant trend of positive association with cleft lip and palate [16].

The rs642961 SNP showed slight variations in European populations, ranging from 24\% to $25 \%$ [31], and in Hispanic and non- 
Hispanic populations $22 \%$ and $25 \%$, respectively [44]. However, in Han Chinese populations, it was reported as low as $15 \%$ [45]. The IRF6 enhancer polymorphism (rs642961) exhibited a dose-dependent effect of A allele with cleft lip alone, but not cleft palate alone [31, 46]. A highly significant association between rs642961 and NSCLP was observed in Central Europe [47, 48], Poland [49], and China populations [42, $50,51]$. In contrast to this, negative association was found in Brazilian [20,52], Spanish Honduras [39], Swedish, and Finnish NSCLP families [53].

In conclusion, while IRF6 is strongly associated in other populations, this study demonstrated that variants in IRF6 may play a role in NSCLP in a south Indian population, but it is expected that other genes may play a role in this population as well.

Conflict of interest: There are no conflicts of interests.

Acknowledgements: The authors acknowledge funding from the Indian Council of Medical Research (ICMR), Government of India (Project Ref. No. 56/15/2007-BMS).

\section{References}

1. Current concepts in genetics of nonsyndromic clefts; Murthy J, Bhaskar L; Indian J Plast Surg. 2009;42(1):68-81. epub date: 2009/11/03. PIMD:19881024.

2. Face facts: genes, environment, and clefts; Murray JC; Am J Hum Genet. 1995;57(2):22732.epub date:1995/08/01. PIMD:7668246.

3. Genetics of cleft lip and palate: syndromic genes contribute to the incidence of nonsyndromic clefts; Stanier P, Moore GE; Hum Mol Genet. 2004;13 Spec No 1:R73-81.epub date:2004/01/15.PIMD:14722155.

4. Splitting p63; van Bokhoven $\mathrm{H}$, Brunner HG; Am J Hum Genet. 2002;71(1):1-13.epub date:2002/05/31.PIMD:12037717.

5. Craniofacial expression of human and murine TBX22 correlates with the cleft palate and ankyloglossia phenotype observed in CPX patients; Braybrook C, Lisgo S, Doudney K, Henderson D, Marcano AC, Strachan T, et al.; Hum Mol Genet. 2002;11(22):2793-804.epub date:2002/10/11.PIMD:12374769.

6. TBX22 mutations are a frequent cause of cleft palate; Marcano AC, Doudney K, Braybrook C, Squires R, Pa on MA, Lees MM, et al.; J Med Genet. 2004;41(1):68-74.epub date:2004/01/20.PIMD:14729838.

7. Mutations in FOXC2 (MFH-1), a forkhead family transcription factor, are responsible for the hereditary lymphedema-distichiasis syndrome; Fang J, Dagenais SL, Erickson RP, Arlt MF, Glynn MW, Gorski JL, et al.; Am J Hum Genet. 2000;67(6):1382-8.epub date:2000/11/15.PIMD:11078474
8. FOXC2 truncating mutation in distichiasis, lymphedema, and cleft palate; Bahuau M, Houdayer C, Tredano M, Soupre V, Couderc R, Vazquez MP; Clin Genet. 2002;62(6):470-3.epub date:2002/12/18.PIMD:12485195.

9. A novel loss-of-function mutation in TTF-2 is associated with congenital hypothyroidism, thyroid agenesis and cleft palate; Castanet $M$, Park SM, Smith A, Bost M, Leger J, Lyonnet S, et al.; Hum Mol Genet. 2002;11 (17):2051-9.epub date:2002/08/08.PIMD:12165566.

10. Fistula labii inferioris congenita and its association with cleft lip and palate; Van Der Woude A; Am J Hum Genet. 1954;6(2):244-56.epub

11. A preliminary gene map for the Van der Woude syndrome critical region derived from $900 \mathrm{~kb}$ of genomic sequence at 1q32-q41; Schutte BC, Bjork BC, Coppage KB, Malik MI, Gregory SG, Scott DJ, et al.; Genome Res. 2000;10(1):8194.epub date:2000/01/25.PIMD:10645953.

12. Mutations in IRF6 cause Van der Woude and popliteal pterygium syndromes; Kondo S, Schutte BC, Richardson RJ, Bjork BC, Knight AS, Watanabe Y, et al.; Nat Genet. 002;32(2):2859.epub date:2002/09/10.PIMD:12219090.

13. A combined targeted mutation analysis of IRF6 gene would be useful in the first screening of oral facial clefts; Wu-Chou YH, Lo LJ, Chen KT, Chang CS, Chen YR; BMC Med Genet. 2013;14:37. epub date:2013/03/21. PIMD:23510002.

14. Comparative analysis of IRF6 variants in families with Van der Woude syndrome and popliteal pterygium syndrome using public whole-exome databases; Leslie EJ, Standley J, Compton J, Bale S, Schutte BC, Murray JC; Genet Med. 2012.epub date:2012/11/17.PIMD:23154523.

15. IRF family of transcription factors as regulators of host defense; Taniguchi T, Ogasawara K, Takaoka A, Tanaka N; Annu Rev Immunol. 001;19:623-55. epub date:2001/03/13. PIMD:11244049.

16. Interferon regulatory factor 6 (IRF6) gene variants and the risk of isolated cleft lip or palate; Zucchero TM, Cooper ME, Maher BS, DaackHirsch S, Nepomuceno B, Ribeiro L, et al.; N Engl J Med. 2004;351(8):769-80. epub date:2004/08/20. PIMD:15317890.

17. Breakthroughs in the genetics of orofacial clefting; Mangold E, Ludwig KU, Nothen MM; Trends Mol Med. 2011;17(12):725-33.epub date:2011/09/03.PIMD:21885341.

18. Genome-wide meta-analyses of nonsyndromic cleft lip with or without cleft palate identify six new risk loci; Ludwig KU, Mangold E, Herms S, Nowak S, Reutter H, Paul A, et al.; Nat Genet. 2012;44(9):968-71.epub date:2012/08/07.PIMD:22863734.

19. Molecular Cloning: A Laboratory Manual., Cold Spring Harbor Laboratory Press, Cold Spring Harbor, NY.; Sambrook J, Fritsch EF, Maniatis T. 1989. epub

20. Lack of association between IRF6 polymorphisms (rs2235371 and rs642961) and nonsyndromic cleft lip and/or palate in a Brazilian population; Paranaiba LM, Bufalino A, MartelliJunior $\mathrm{H}$, de Barros LM, Graner E, Coletta RD; Oral Dis. 2010;16(2):193-7.epub date:2009/09/29. PIMD:19780991.
21. Population genetics of a functional variant of the dopamine betahydroxylase gene (DBH); Cubells JF, Kobayashi K, Nagatsu T, Kidd KK, Kidd JR, Calafell F, et al.; Am J Med Genet. 1997;74(4):374-9.epub date:1997/07/25. PIMD:9259372.

22. Haploview: analysis and visualization of LD and haplotype maps; Barrett JC, Fry B, Maller J, Daly MJ; Bioinformatics. 2005;21(2):263-5.epub date:2004/08/07. PIMD:15297300.

23. Arlequin suite ver 3.5: a new series of programs to perform population genetics analyses under Linux and Windows; Excoffier L, Lischer $\mathrm{HE}$; $\mathrm{Mol}$ Ecol Resour. 2010;10(3):564-7.epub date:2011/05/14. PIMD:21565059.

24. Multifactor dimensionality reduction software for detecting gene-gene and gene-environment interactions; Hahn LW, Ritchie MD, Moore JH; Bioinformatics. 2003;19(3):376-82.epub date:2003/02/14. PIMD:12584123.

25. Virus-induced heterodimer formation between IRF-5 and IRF-7 modulates assembly of the IFNA enhanceosome in vivo and transcriptional activity of IFNA genes; Barnes BJ, Field AE, PithaRowe PM; J Biol Chem. 2003;278 (19):1663041.epub date:2003/02/26. PIMD:12600985.26.

26. Abnormal skin, limb and craniofacial morphogenesis in mice deficient for interferon regulatory factor 6 (Irf6); Ingraham CR, Kinoshita A, Kondo S, Yang B, Sajan S, Trout KJ, et al.; Nat Genet. 2006;38(11):1335-40. epub date:2006/10/17. PIMD:17041601.

27. Irf6 is a key determinant of the keratinocyte proliferation-differentiation switch; Richardson RJ, Dixon J, Malhotra S, Hardman MJ, Knowles L, Boot-Handford RP, et al.; Nat Genet. 2006;38(11):1329-34. epub date:2006/10/17. PIMD:17041603.

28. Genome-wide analysis of $\mathrm{p} 63$ binding sites identifies AP-2 factors as coregulators of epidermal differentiation; McDade SS, Henry AE, Pivato GP, Kozarewa I, Mitsopoulos C, Fenwick K, et al.; Nucleic Acids Res. 2012;40(15):7190206. epub date:2012/05/11. PIMD:22573176.

29. Interaction between IRF6 and TGFA genes contribute to the risk of nonsyndromic cleft lip/palate; Letra A, Fakhouri W, Fonseca RF, Menezes R, Kempa I, Prasad JL, et al.; PLoS ONE. 2012;7(9):e45441. Epub date:2012/10/03. PIMD:23029012.

30. Smad4-Irf6 genetic interaction and TGF betamediated IRF6 signaling cascade are crucial for palatal fusion in mice; Iwata J, Suzuki A, Pelikan RC, Ho TV, Sanchez-Lara PA, Urata M, et al.; Development. 2013;140(6):1220-30. epub date:2013/02/15. PIMD:23406900.

31. Disruption of an AP-2alpha binding site in an IRF6 enhancer is associated with cleft lip; Rahimov F, Marazita ML, Visel A, Cooper ME, Hitchler MJ, Rubini $\mathrm{M}$, et al.; Nat Genet. 2008;40(11):1341-7.epub date:2008/10/07. PIMD:18836445.

32. Strong evidence of linkage disequilibrium between polymorphisms at the IRF6 locus and nonsyndromic cleft lip with or without cleft palate, in an Italian population; Scapoli L, Palmieri A, Martinelli M, Pezzetti F, Carinci P, Tognon M, et al.; Am J Hum Genet. 2005;76(1):1803.epub date:2004/11/24. PIMD:15558496. 
33. Variation in IRF6 contributes to nonsyndromic cleft lip and palate; Blanton $\mathrm{SH}$, Cortez A, Stal S, Mulliken JB, Finnell RH, Hecht JT; Am J Med Genet A. 2005;137A(3):259-62.epub date:2005/08/13. PIMD:16096995.

34. Interferon regulatory factor-6: a gene predisposing to isolated cleft lip with or without cleft palate in the Belgian population; Ghassibe $\mathrm{M}$, Bayet B, Revencu N, Verellen-Dumoulin C, Gillerot $Y$, Vanwijck R, et al.; Eur J Hum Genet. 2005;13(11):1239-42.epub date:2005/09/01. PIMD:16132054

35. Significant association between IRF6 820G->A and non-syndromic cleft lip with or without cleft palate in the Thai population; Srichomthong C, Siriwan P, Shotelersuk V; J Med Genet. 2005;42(7):e46. Epub date:2005/07/05. PIMD:15994871.

36. 844ins68 in the cystathionine beta-synthase gene in Israel and review of its distribution in the world; Zoossmann-Diskin A, Gazit E, Peleg L, Shohat M, Turner D; Anthropol Anz. 2004;62(2):147-55. Epub date:2004/07/02. PIMD:15228193.

37. Linkage disequilibrium between IRF6 variants and nonsyndromic cleft lip/palate in the Chilean population; Suazo J, Santos JL, Jara L, Blanco R; Am J Med Genet A. 2008;146A(20):27068.epub date: 2008/09/18. PIMD:18798331.

38. Association between IRF6 SNPs and oral clefts in West China; Huang Y, Wu J, Ma J, Beaty TH, Sull JW, Zhu L, et al.; J Dent Res. 2009;88(8):715-8.epub date:2009/09/08. PIMD:19734457.

39. Association of common variants, not rare mutations, in IRF6 with nonsyndromic clefts in a Honduran population; Larrabee YC, Birkeland AC, Kent DT, Flores C, Su GH, Lee JH, et al.; Laryngoscope. 2011;121(8):1756-9. epub date:2011/07/28. PIMD:21792966.

40. Genetic variants in IRF6 and the risk of facial clefts: single-marker and haplotype-based analyses in a population-based case-control study offacial clefts in Norway; Jugessur A, Rahimov F, Lie RT, Wilcox AJ, Gjessing HK, Nilsen RM, et al.; Genet Epidemiol. 2008;32(5):413-24. epub date:2008/02/19. PIMD:18278815.

41. The IRF6 p.274V polymorphism is not a risk factor for isolated cleft lip; Hering $R$, Grundmann K; Genet Med. 2005;7(3):209; author reply $\quad-10$. Epub date:2005/03/19. PIMD:15775759.

42. Association Between Interferon Regulatory Factor 6 Gene Polymorphisms and Nonsyndromic Cleft Lip With or Without Cleft Palate in a Chinese Population; Zhou Q, Li M, Zhu W, Guo J, Wang Y, Li Y, et al.; Cleft Palate Craniofac J. 2013. epub date:2013/03/21. PIMD:23509905.

43. MTHFR 677TT alone and IRF6 820GG together with MTHFR 677CT, but not MTHFR A1298C, are risks for nonsyndromic cleft lip with or without cleft palate in an Indian population; Ali A, Singh SK, Raman R; Genet Test Mol Biomarkers. 2009;13(3):355-60.epub date:2009/05/08. PIMD:19419265

44. Ethnic Heterogeneity of IRF6 AP-2a Binding Site Promoter SNP Association With Nonsyndromic Cleft Lip and Palate; Blanton SH, Burt A, Garcia E, Mulliken JB, Stal S, Hecht JT; Cleft Palate Cra- niofac J. 2010;47(6):574-7. epub date:2010/11/03. PIMD:21039277.

45. Low erythrocyte folate status and polymorphic variation in folate-related genes are associated with risk of neural tube defect pregnancy; Relton $\mathrm{CL}$, Wilding $\mathrm{CS}$, Laffling AJ, Jonas PA, Burgess $\mathrm{T}$, Binks K, et al.; Mol Genet Metab. 2004;81(4):273-81.epub date:2004/04/03. PIMD:15059614.

46. Genome scan, fine-mapping, and candidate gene analysis of nonsyndromic cleft lip with or without cleft palate reveals phenotype-specific differences in linkage and association results; Marazita ML, Lidral AC, Murray JC, Field LL, Maher BS, Goldstein McHenry T, et al.; Hum Hered. 2009;68(3):151-70.epub date:2009/06/13. PIMD:19521098.

47. Polymorphisms in the folate-metabolizing genes MTR, MTRR, and CBS and breast cancer risk; Weiner AS, Boyarskikh UA, Voronina EN, Selezneva IA, Sinkina TV, Lazarev AF, et al.; Cancer Epidemiol. 2012;36(2):e95-e100. epub date:2012/01/13. PIMD:22236648.

48. IRF6 gene variants in Central European patients with non-syndromic cleft lip with or without cleft palate; Birnbaum S, Ludwig KU, Reutter $\mathrm{H}$, Herms S, de Assis NA, Diaz-Lacava A, et al.; Eur J Oral Sci. 2009;117(6):766-9. epudate:2010/02/04. PIMD:20121942.

49. Association between genetic variants of reported candidate genes or regions and risk of cleft lip with or without cleft palate in the polish population; Mostowska A, Hozyasz KK, Wojcicki P, Biedziak B, Paradowska P, Jagodzinski PP; Birth Defects Res A Clin Mol Teratol. 2010;88(7):538-45. epub date:2010/06/15. PIMD:20544801.

50. Single-nucleotide polymorphisms (SNPS) of the IRF6 and TFAP2A in nonsyndromic cleft lip with or without cleft palate (NSCLP) in a northern Chinese population; Shi J, Song T, Jiao X, Qin C, Zhou J; Biochem Biophys Res Commun. 2011;410(4):732-6.epub date:2011/06/21. PIMD:21683068.

51. IRF6 polymorphisms are associated with nonsyndromic orofacial clefts in a Chinese Han population; Pan Y, Ma J, Zhang W, Du Y, Niu Y, Wang $\mathrm{M}$, et al.; Am J Med Genet $A$. 2010;152A(10):2505-11. epubdate:2010/08/28. PIMD:20799332.

52. IRF6 is a risk factor for nonsyndromic cleft lip in the Brazilian population; Brito LA, Bassi CF, Masotti C, Malcher C, Rocha KM, Schlesinger D, et al.; Am J Med Genet A. 2012;158A(9):2170-5. epub date:2012/08/14. PIMD:22887868.

53. Association and Mutation Analyses of the IRF6 Gene in Families With Nonsyndromic and Syndromic Cleft Lip and/or Cleft Palate; Pegelow M, Koillinen $H$, Magnusson M, Fransson I, Unneerg $\mathrm{P}$, Kere J, et al.; CleftPalate Craniofac J. 2013. epub date:2013/02/12. PIMD:23394314. 